\title{
Competency Requirements for Effective Job Performance in The Thai Public Sector
}

\author{
Vichita Vathanophas \\ Mahidol University \\ E-mial: vichita.v@cmmu.net \\ Jintawee Thai-ngam \\ Mahidol University \\ E-mail: jintaweethaingam@yahoo.com
}

\begin{abstract}
Human assets are one of the most important resources available to any organization and employee competence and commitment largely determine the objectives that an organization can set for itself and to its success in achieving them. Therefore, the demand for effective employees continuously increases in both public and private organizations. The 'Competency-based' approach to human resource management has become integral during the last thirty years, with 'Competency' encompassing the knowledge, skills, abilities, traits and behaviors that allow an individual to perform a task within a specific function or job (Boyatzis, 1982).

The objective of this study is to identify the required competencies and develop a competency model for effective job performance at the Chief of the General Administrative Sub-Division position level in the Thai Department of Agriculture using the Behavioral Event Interview (BEI) technique (Spencer \& Spencer, 1993). The study found that there were twenty-three competencies that superior job performers used in carrying out this job well. Consequently, the researcher uses current level of importance of competency as primary information to recommend nine competencies in a competency model.

This competency model will help the Thai Department of Agriculture to respond to government policy regarding human resource management, provide useful information
\end{abstract}


about the specific characteristics required at the Chief of the General Administrative SubDivision level and on how to implement further enhancement of employee performance at this level. These competencies will also enable the Department to determine the critical competencies necessary for current success at this job level and the strategic competencies necessary for future success.

Keywords: Competency Model, Job Performance, Human Resource Management

\section{INTRODUCTION}

Competent employees are the main resource of any organization in acquiring a competitive advantage. Land, buildings or materials do not yield company productivity, rather, it is 'people capital' that runs a business and produces value from existing resources. HayGroup (2004) point out that an organization's best source of competitive advantage lies with its employees. Strategies, business models, products and services can all be copied by competitors, but talented and competent employees represent a sustainable source of differentiation. The demand for effective and competent employees continuously increases in both public and private organizations because a dynamic global marketplace and increasing foreign competition has compelled organizations to become more effective and flexible in response to the rapidly changing environment. As a result, this is a suitable time to assess human resource management (HRM) practices that can augment organizational performance in public sector organizations (Gould-Williams, 2003). Organizations try to increase their capabilities by investing more in training and management development and Ichniowski et al. (1996) state that HRM practices have a greater effect on organizational performance than on individual performance. Moreover, human resource development encourages competency development by forming opportunities within the organization for employees to develop their competencies for both their own benefit and the benefit of others (Rao, 2000a; Rodrigues \& Chincholkar, 2005). The competency-based approach has become integral in HRM during the last thirty years and, currently, different organizations, businesses and public services use competency models to better integrate global trends and business strategies with their human capital resources. Competency encompasses the knowledge, skills, abilities, traits and behaviors that allow an individual to perform a task within a specific function or job. In accordance with this approach, competencies are used as the basis for human resource management.

Carretta (1992) suggests that the best way of matching people and jobs is through 
the use of competency modeling. Competency models help organizations to take a more unified and coordinated approach in designing improvements to HRM systems, including job redesign, recruitment, organizational learning, career management, performance improvements and compensation systems (United Nations Industrial Development Organization, 2002). In implementing effective HRM the introduction of competency building programs for each job or task should be considered, as an employee's competencies are usually linked to their job and, hence, to organizational performance. Therefore, improving employee competencies would improve both job and organizational performance and an organization needs to hone the competencies of individual employees to support a competitive strategy.

The Thai public today expects the Thai Government to become more citizen focused and to operate in a more businesslike manner; forcing public sector organizations to increase accountability, quality and effectiveness in order to develop greater public trust and confidence in the government. Faced with many of the same pressures as the private sector; such as the impact of globalization and the economic crisis, public sector organizations are using many methods to transform into citizen and customer-driven, high performance and result-oriented organizations. To meet public expectations, the Thai Government is attempting to change public sector operations by implementing public sector management reform. The public sector management reform plan aims to create a civil service based on merit and focusing on benefits to the nation and the Thai people, which is trustworthy, has integrity and courage, is transparent and accountable, and is up-to-date, forward looking and result oriented. The five key reform areas are (1) structural reform, (2) budgetary and financial reform, (3) human resources management (HRM) reform, (4) law reform and (5) cultural and value reform, and cover both system and human resource aspects of the Thai civil service.

In terms of HRM reform, HRM strategies have been launched that focus on reviewing and improving the roles and missions of all existing civil service employees to increase the number of high quality employees in all public sector organizations. In its strategies the government is using a competency-based approach to HRM for the public sector and, as a consequence, public sector organizations are committed to proceed with human resource development plans based on the competency-based approach (Office of Civil Service Commission (OCSC), 2003). The Department of Agriculture is a public sector organization that is developing a HRM competency-based model in line with government strategy and necessary bureaucratic reform. In order to respond to 
government policy regarding a competency-based approach, and to support becoming a learning organization, the Department needs to conduct research and develop the competencies of its employees in order to utilize its human resources as the main tool to organizational success. This study, therefore, has the primary objective of identifying the required competencies for effective job performance of employees in general administration in the Department of Agriculture. Competency building for employees at this level will increase their work potential and thereby fulfill Departmental capacity to manage the organization effectively through its human assets. The findings of this study will benefit in formulating a human resource management plan based on the competencybased approach.

This paper is divided into five sections. Section I reviews related literature on the definition of competency and the linkage between competency and Thai Civil Service Development Policy. Section II explains the Behavior Event Interview (BEI) technique. Section III presents the conceptual framework of the study and the research methodology used in analyzing and interpreting the data. Section IV presents the data analysis and results of the study. Section $\mathrm{V}$ provides recommendations, the implications of the study and conclusions

\section{LITERATURE REVIEW}

\section{Competency}

The term competency was probably first introduced to psychology literature in 1973 when David McClelland argued in his article 'Testing for competence rather than for intelligence' that traditional tests of academic aptitude and knowledge content in fact predicted neither job performance nor success in life. Thus, the quest for theory and tools that could reliably predict effectiveness in the workplace began (McClelland, 1973). In 1982 it was Boyatzis who first drew together comprehensive data that had been collected in the USA using the McBer \& Company 'Job Competence Assessment' method. Since then, competency has become a significant factor in HR development practices (Simpson, 2002).

The word competency comes from a Latin word meaning "suitable" (Bueno \& Tubbs, 2004). Boyatzis (1982) defines a competency as "an underlying characteristic of a person which results in effective and/or superior performance in a job” (p. 97). According to Boyatzis (1982) a job competency represents ability. An individual's set of 
competencies reflect their capability or what they can do. A job competency may be a motive, trait, skill, aspect of one's self-image or social role, or a body of knowledge that an individual uses, and the existence and possession of these characteristics may or may not be known to the individual. Similarly, Mitrani et al. (1992) state that competencies could be motives, traits, self-concepts, attitudes or values, content knowledge, or cognitive or behavioral skills.

A competency is an individual characteristic that can be measured or counted reliably and that can be shown to differentiate significantly between superior and average performers, or between effective and ineffective performers. Meanwhile, competency can be described as a set of behavior patterns that an incumbent needs to bring to a position in order to perform its tasks and functions in the delivery of desired results or outcomes (Bartram, et. al, 2002; Woodruffe, 1992). Spencer and Spencer (1993) viewed competency as "an underlying characteristic of an individual that is causally related to criterion-referenced effective and/or superior performance in a job or situation” (p. 9). They identified five types of competency characteristics consisting of motives, traits, self-concept, knowledge and skills. First, motives are the things that an individual consistently thinks about or wants that stimulate action. Motives drive, direct and select behavior toward certain actions or goals and away from others. Second, traits are physical characteristics and consistent responses to situations or information. Third, self-concept is an individual's attitudes, values or self-image. Fourth, knowledge is the information that an individual has in specific content areas. Finally, skill is the ability to perform a certain physical or mental task. Knowledge and skill competencies tend to be visible and relatively surface characteristics, whereas self-concept, traits and motive competencies are more hidden, deeper and central to personality. Surface knowledge and skill competencies are relatively easy to develop and training is the most cost-effective way to secure those employee abilities (Spencer \& Spencer, 1993). Figure 1 illustrates central and surface competencies. 


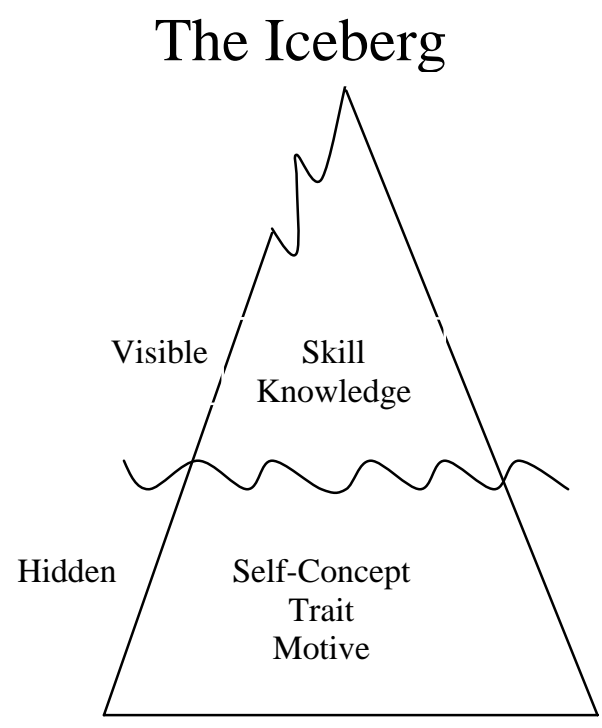

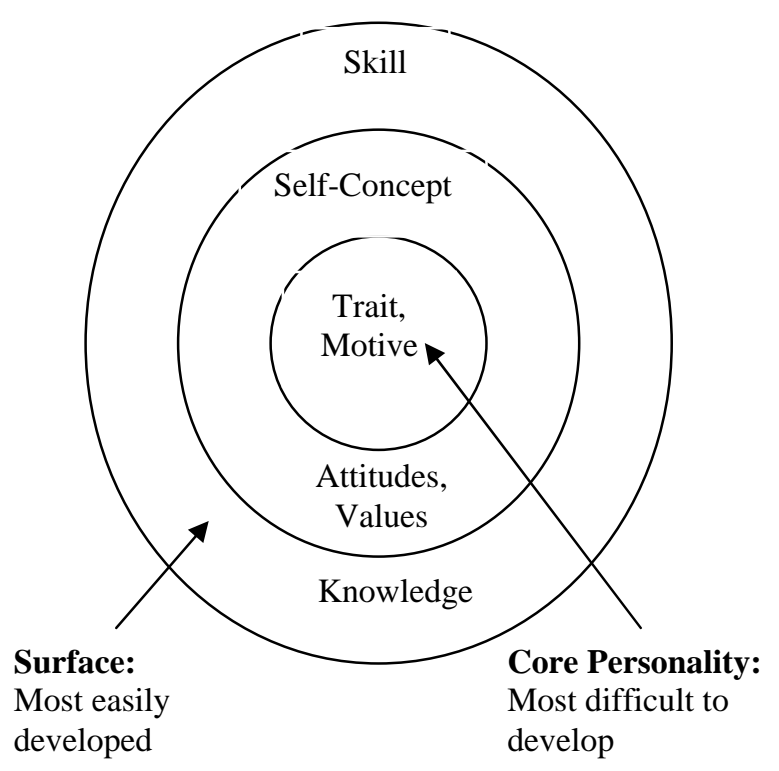

Figure 1 The Iceberg Model and Central and Surface Competencies Source: Spencer and Spencer (1993: 11)

In other words, visible competencies such as knowledge and skills may be somewhat technical competencies basically required by the job, whereas hidden competencies such as self-concept, traits and motives are behavioral competencies that drive an individual's performance in the job. Boyatzis (1982) states that motive and trait competencies have the most direct impact on self-concept and also have an impact on skill. The United Nations Industrial Development Organization (UNIDO, 2002) defines competency as a set of skills, related knowledge and attributes that allow an individual to perform a task or activity within a specific function or job. If an individual possesses these three elements of competency they can effectively perform duties as required by the specific job.

From the wide range of related literature, the definition of competency can be summarized as an underlying characteristic of an individual that is causally related to criterion-referenced effective and/or superior performance in a job or situation. Job competency is a set of behavior patterns that a job incumbent needs to bring to a position in order to perform its tasks and functions with competence. A job competency can be a motive, trait, skill, self-concept, body of knowledge or an attribute that allows an individual to perform a task or activity within a specific function or job. Skill and 
knowledge are surface or technical competencies that can be developed easily by training. On the other hand, motives, traits and self-concept are hidden or behavioral competencies that are difficult to develop. Traditionally, it is essential for an individual to possess the required technical competencies at a threshold level in order to adequately perform their job. However, the changing environment and diverse workforce has resulted in behavioral competencies becoming crucial as the greatest determinants of an individual's performance. Thus, in order to be effective in a job, individuals needs to possess or acquire both technical and behavioral competencies and use these together in performing their tasks.

\section{Values of Competency}

The value of competency has been widely explored. For example, in the 1990's the LBA Consulting Group conducted a study that focused on identifying the factors that most contributed to the creation and sustenance of organizational excellence. The study examined organizations that had survived and prospered, and those that had failed, over a 25-year period. The results of the study suggested that six human resource conditions have to be met. These conditions were a performance-oriented culture, low turnover, high levels of employee satisfaction, a cadre of qualified replacements, effective investment in employee compensation and development, and the use of institutional competencies (success factors) in employee selection and performance evaluation processes (Berger \& Berger, 2004). Mitrani et al. (1992) mention the need for competency and predict that organizations of the future will be built around people. They add that there will be less emphasis on jobs as the building blocks of an organization; instead increased attention will be focused on employee competence. If we are using people as the building blocks of an organization, then competence or what they bring to the job becomes crucial. The competency approach to selection and assessment is based on classifying, identifying, and measuring individual differences for particular work-related constructs that are relevant to successful job performance (Bartram, 2004). Cummings and Worley (2001) similarly state that organizational changes frequently demand new knowledge, skills and behavior from employees. They argue that in many cases changes could not be implemented unless employees gained new competencies. They also suggest that change agents are needed to provide multiple learning opportunities, such as traditional training programs, on-the-job counseling and coaching, and experiential simulations, covering both technical and social skills, and that it must be ensured that such learning occurs. 
The Society for Human Resource Management (2003) has indicated that competencies have become integral in the field of HRM. The Society cite supporting evidence showing that in the last thirty years the competency approach has emerged from being a specialized and narrow application to being a leading technique for diagnosing, framing and improving most aspects of HRM. According to the Society, a new competency model was necessary because the business world was changing at an unprecedented rate. These changes require HR professionals to add significant value and to do so quickly. Moreover, since HRM activities directly impact company ability to compete, competency models need to be continually researched and updated (Society for Human Resource Management, 2003). Thomson and Strickland (2004) also place building core competencies and competitive capabilities as a key component of building a capable organization. They state that building core competencies and competitive capabilities will enable good strategy execution and that maintenance of a competence/capability portfolio, that is updated as strategy and external conditions change, will guarantee that an organization is capable of effective strategy execution. From the literature cited above it can be summarized that, during the last thirty years, competency has become a key factor in HRM in terms of building a capable organization. This is because academic or knowledge content alone is insufficient for an individual to be successful in their job. Rather, desired characteristics or behavior are meaningful in ensuring that an individual is effective in performing their tasks according to the job demands. People capital has become a valuable asset to both current and future organizations. Therefore competence needs to be focused and, if we are using people as the building blocks of the organization, then their competence becomes crucial.

The linkage between competency and job performance is addressed by Boyatzis in "Model of Effective Job Performance" (1982: p. 13). This model specifies that effective action, and therefore performance, will occur when all three of the critical components, i.e. organizational environment, job demands, and an individual's competencies, are consistent or fit. This means that if any one or two of those components are inconsistent and do not correspond with each other, then ineffective behavior or inaction will result. A graphic representation of this model is illustrated in Figure 2 below. 


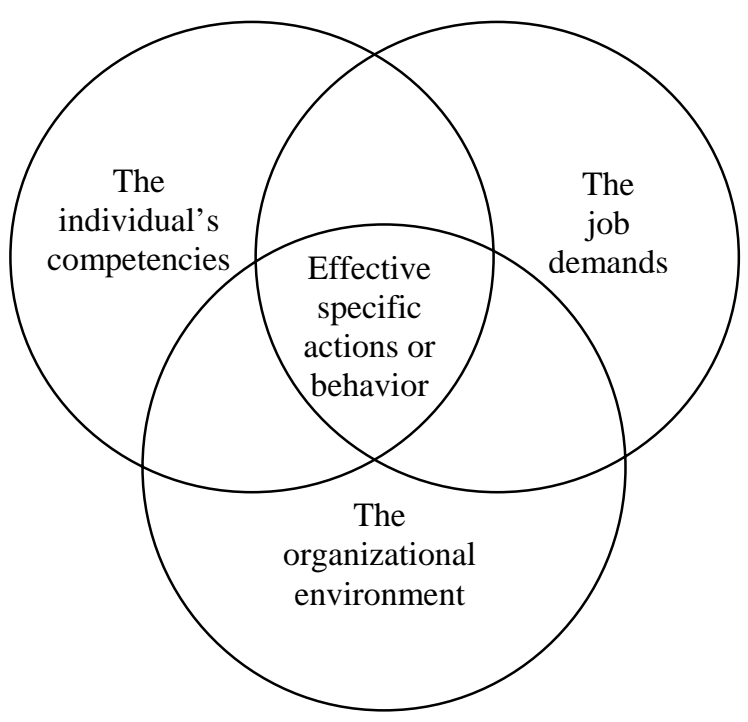

Figure 2 A Model of Effective Job Performance Source: Boyatzis (1982: 13)

According to this model an individual's competencies represent capability that the individual brings to the job situation as required by the responsibilities of the job. These job requirements can be considered the job demands on an individual. Competencies are certain characteristics or abilities of an individual that enable them to demonstrate appropriate specific actions. Effective job performance is the attainment of specific results or outcomes required by the job through those specific actions while maintaining or being consistent with policies, procedures and conditions of the organizational environment. In summary, the job demands component reveals primarily what an individual is capable of doing; and reveals why they may act in certain ways (Boyatzis, 1982). In order to identify the job-specific competencies that will fit with the other two elements of the model of effective job performance, mentioned previously, the researchers used a concept from the preceding model as a guideline for this study. The required competencies for effective performance at the position level of Chief of General Administrative Sub-Division in the Department of Agriculture will be determined as being consistent with the job demands and also the organizational environment. 


\section{Competency as a Critical Factor of Thai Civil Service Development Policy}

To obtain a competitive advantage and survive in the current dynamic world, Thailand has adapted in many contexts to respond to changing trends and one key factor that has been primarily examined is human capital. In 2003 the need for competent civil servants was determined when the Thailand Office of Civil Service Commission (OCSC) conducted a "Research Study to Develop Policies, Mechanisms and Follow-up Evaluation of Government Officials Development”. From the results of that study the research team submitted a draft Civil Service Development Policy which stated that competency development of government officials must be based on a set of pre-defined competencies and virtues required for each position holder (OCSC, 2003). The Thai Government realizes the necessity for a competent workforce and the 2003-2007 strategic plan for a new bureaucratic system states that every public organization has a commitment to conduct a human resource development plan based on organizational vision, mission, objectives and a competency-based approach (OCSC, 2004). According to OCSC there are related components in the process of developing a human resource development strategy plan, shown in Figure 3.

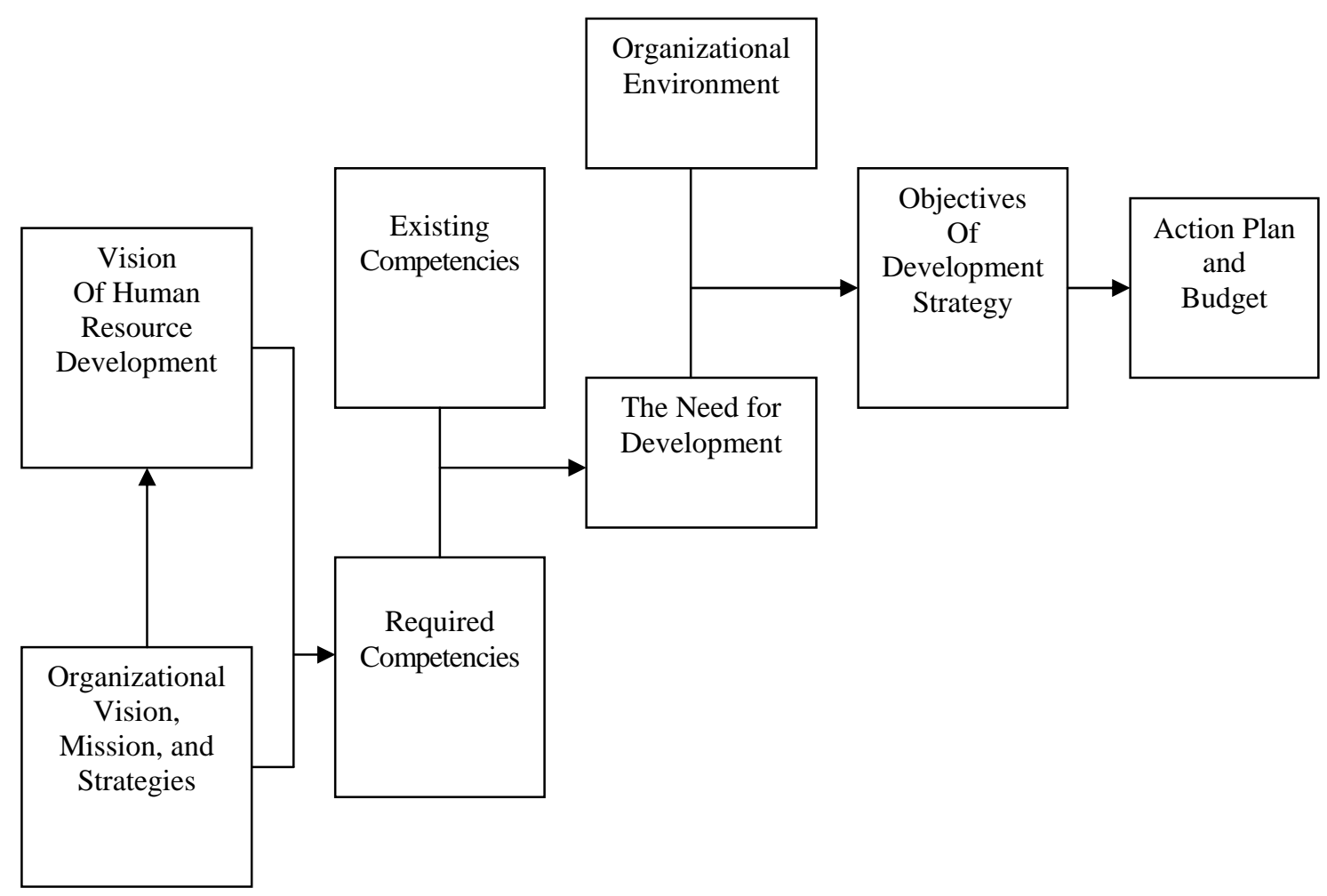

Figure 3 The Process of Developing Human Resource Development PlanSource: OCSC, 2004 
In order to develop a human resource development plan an organization has a primary duty to clarify its organizational vision, mission and strategies. The vision for human resource development can then be defined. Next, the work in each field needs to be determined by job descriptions and then the competency requirements for each position level can be investigated. The competency gap, or gap between expected and existing competence, also needs to be assessed because this is considered as a measure of the need for development of public sector employees. Meanwhile, it is crucial that HR development policies are aligned with the organizational environment, such as budget, stakeholders and time periods. It is necessary that appropriate strategies are used in conducting HR development based on target groups, required competencies, available resources, and include opportunities and threats. An action plan and required budget can then be set (OCSC, 2004). The need for development of Thai civil servants is determined by the Office of Civil Service Commission (OCSC) which specifies that the need for development of government officials is considered as the gap between existing and required competencies. This refers to the required competence at work in order to meet ultimate goals according to the organizational vision and strategies. Thus, the need for competency development of government officials at each position level should be identified through the requirements of organizational vision, mission and strategies. This need can be fulfilled by setting a competency model for each separate position level. Competency requirements and competency gap can be explored by conducting research and the appropriate methods for competency modeling are interviews, questionnaires and seminars, or a focus group of key stakeholders (OCSC, 2004).

The objective of this study is to identify the required job-specific competencies for effective performance at Chief of General Administrative Sub-Division position level in the Department of Agriculture. The nature of positions at this level is that of entry-level management in general administrative or support. The researchers examined the available literature to find how competency study design and competency modeling should be conducted (Puwittayaphan, 2004; Rassametummachot, 2005: Saenthong, 2004; Spencer \& Spencer, 1993). Firstly, this study was systematically conducted by identifying a group of superior performers at this position level. Next, data on how to perform effectively at this position level was gathered from superior performers. The data collected was then analyzed to identify competencies and develop a competency model. In addition, the model was validated in order to assure that it really represented the competencies required at this position level. In order to identify the required 
competencies that would support effective performance at the position level of Chief of General Administrative Sub-Division in the Department of Agriculture, this study applied the methods specified by Spencer and Spencer, and recommended by Puwittayaphan, Saenthong, and Rassametummachot as guidance for the research. First, the on-hand job description was examined for key accountabilities of the job. Second, the job description and definition of a superior performer were used as performance effectiveness criteria. Third, superior performers were selected as criteria samples. The Behavioral Event Interview (BEI) method was then used in data collection and the interview narratives analyzed or coded for competency themes. Finally, the predefined competency model was validated by asking key stakeholders to rate each competency according to level of importance for effective job performance. The process of competency study and research methodology is explained in detail in the next section.

\section{THE BEHAVIORAL EVENT INTERVIEW (BEI) TECHNIQUE}

The Behavioral Event Interview (BEI) technique was used for data collection as this is one of the most effective techniques for assessing managerial behavior. The criticalincident Behavioral Event Interview (BEI) technique was developed by David C. McClelland, a professor of psychology at Harvard University, and colleagues at McBer \& Company (Spencer \& Spencer, 1993). The BEI technique can be considered a contentvalid assessment method of obtaining a sample of a individual actual behavior in a job. Using an interview format, an individual's sequence of thoughts and feelings can be obtained that may directly relate to effective performance but not be directly observable to someone else in that individual's presence. The BEI provides a sample of an individual's behavior that results in information about critical incidents in the individual's recent job activity. This allows for documentation of a pattern for demonstrating specific competencies. The BEI technique is conducted by asking the interviewee to describe incidents in which they felt effective in the job and incidents in which they felt ineffective in the job. The result of the interview is a detailed description of a number of critical incidents on the job in which the interviewee's behavior and their thoughts and feelings are documented. These events can be systematically coded for various characteristics, or competencies. The coding of characteristics is then related to performance criteria using the Competency Dictionary and conceptualizing new competency themes from the interview narratives (Spencer and Spencer, 1993).

Berger and Berger (2004) show that the BEI technique provides a wealth of narrative 
data that can be used to develop case studies and training exercises by showing what the best performers actually did in the most critical situations they faced. The BEI is openended, so analysts can discover and code new competencies, as well as those in existing dictionaries. The BEI consistently shows the highest reliability and validity in predicting future employee performance. Following are key BEI questions used to ask interviewees about the most critical situations they have faced in their jobs: peak high points and peak low points.

- What was the situation? This can be scored by analysts for which situations the interviewees considered critical (often very different for superior and average performers)

- What led up to the situation? This is coded for whether the interviewee initiated or reacted to the situation, the extent to which they sought information to anticipate or prepare for events.

- Who was involved in the situation? This is coded for the different types of people the interviewee typically interacts with, i.e. no-one, peers, top management, external experts or customers, and in what priority.

- What did the interviewee observe, see, hear, read, and pay attention to in the situation? This is coded for information-seeking and pattern recognition.

- What did the interviewee feel and want to have happen in responding to the situation? This coded for emotional self-control, self-confidence and motivation.

- What did the interviewee think about in analyzing or understanding the situation and deciding whether and how to respond to it? This is coded for conceptual and analytical thinking and strategic planning.

- What did the interviewee actually do? This is coded for behavioral skills, initiative.

- What was the outcome of the situation? This is coded for what the interviewee thinks is an important outcome (achievement, conciliation, achievement, and influence).

It is clear from the preceding questions that the Behavioral Event Interview (BEI) technique is an effective method in collecting narrative data to determine job competencies. This technique identifies the competencies needed to do a job well and the interview is conducted by asking interviewees to focus on the most critical situations they have faced. Stories related about how interviewees handled the most important parts of their job reveal their competencies to do the job. The interview transcripts can be coded 
for competencies using the Competency Dictionary and conceptualizing new competency themes from interview narratives.

\section{RESEARCH METHODOLOGY}

Effective action, and therefore performance, will occur when three critical components: organizational environment, job demands, and the individual's competencies are consistent (Boyatzis, 1982). Thus, in this study, job-specific competencies are identified as being consistent with job demands and organizational environment. Based on these concepts, the conceptual framework of this study is illustrated in Figure 4.

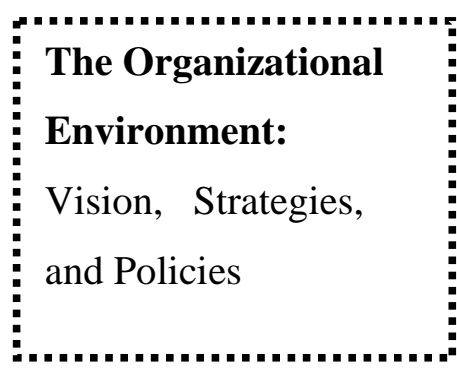

\section{The Job Demands:}

Job Descriptions

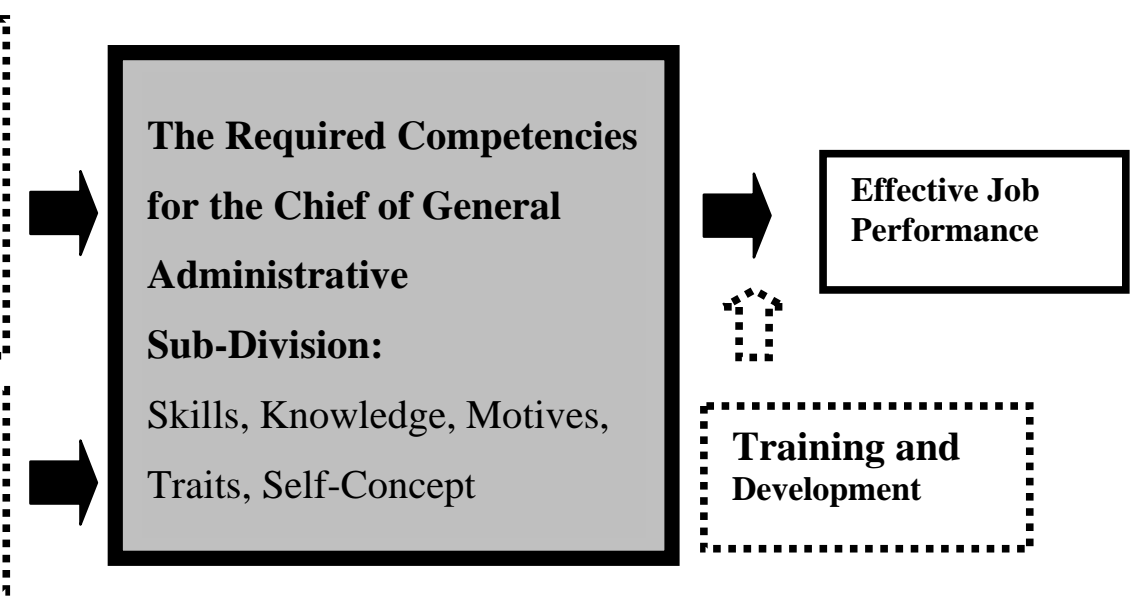

Figure 4 The Conceptual Framework Adapted from A model of Effective Job Performance (Boyatzis, 1982)

Organizational environment can be described in terms of a number of different factors, including strategic position, mission and policies of the organization (Boyatzis, 1982). For this reason, this study assumed the vision, strategies and policies of the Department to be the organizational environment. In order to identify competencies in this study, these factors were included in both the interviews and questionnaire survey.

Job demands as used by Boyatzis (1982) can be described in terms of general functional requirements. Since job description is the job requirement criteria for each distinctive position, this means that the job description can be used as a criterion to identify the required competencies that suit the job. In this study, job description was 
referred to as the demands that identify competencies for the job. The job description for the Chief of General Administrative Sub-Division position level had already been determined by a committee consisting of key department stakeholders. This committee included members at the management level, operational level and with expertise in this field. The job description was determined based on the requirements of the current vision, strategies and policies of the Department and has already been specified as being consistent with the organizational environmental factors. The job description was referred to during the interviews and also attached as a key factor in the competency model survey in order to determine the required competencies that would be congruent with the existing job demands.

Competencies are the certain characteristics or abilities of an individual that enable them to perform appropriate specific actions. Competencies represent the capability that an individual brings to the job. When the responsibilities of the job to produce the desired results require the demonstration of specific actions, an individual draws from inner resources for the capability to respond. Competencies include motive, traits, self-concept, skills and knowledge (Boyatzis, 1982). The main objective of this study is to determine the required competencies for effective performance at the Chief of General Administrative Sub-Division position level in the Department of Agriculture. The job description had already been determined, based on the requirements of the organizational environment and this job description was used to identify job competencies in this study. It can be concluded that the competencies identified are consistent with the organizational environment and also the job demands.

Apart from the organizational environment, job demands and required competencies, this study also included training and development as a component in the conceptual framework. This is because training is an effective approach in developing an individual's competencies. Ivancevich (2003) says that training is the systematic process of altering the behavior of employees in a direction that would achieve organization goals. Training is related to present job skills and abilities; has a current orientation and helps employees master specific skills and abilities needed to be successful. Thomson and Strickland (2004) also state that building employee competencies and competitive capabilities suited to current strategies make an organization capable of good strategy execution, and can be efficiently implemented by providing training for employees. They state that employee training is strategically important in organizational efforts to build skill-based competencies and, if the chosen strategy called for new skills, deeper 
technological capability, or building and using new capabilities, employee training should be high in the organization action agenda. Therefore, in this study, the views of interviewees and respondents on employee training needs were examined in order to gather primary information for further development of employees at the Chief of General Administrative Sub-Division position level, an entry-level manager position in the Department of Agriculture. The study findings will be useful in allowing the Department to design and provide appropriate training and development programs for employees at this position level.

This aim of this study is to identify required competencies for effective performance at the Chief of General Administrative Sub-Division position level in the Department of Agriculture. The study was conducted based on the conceptual framework previously outlined and the required competencies explored in this study were determined to be consistent with the other two elements of an effective job performance, i.e. organizational environment and job demands. This was accomplished by incorporating these two factors in the process of gathering diagnostic data. Moreover, since employee training is an effective way of building job competencies, training needs for employees in this position were also investigated.

In order to identify the required competencies for effective job performance at the Chief of General Administrative Sub-Division position level in the Department of Agriculture, the study was conducted according to the following methods.

1. First, superior performers at this position level were identified.

2. Second, the researchers conducted Behavioral Event Interviews (BEIs) with the superior job performers selected.

3. Third, the BEI data was coded using "thematic analysis" methods, i.e. interview transcripts were coded for known competencies using the Competency Dictionary and by conceptualizing new competency themes from interview narratives (Spencer and Spencer, 1993). The interview narratives from these superior performers were used as primary data to identify job-specific competencies and key behavioral indicators.

4. Fourth, the preliminary competency model was validated by asking key stakeholders to rate each competency based on importance to effective job performance. In this step a competency model survey was conducted and the questionnaire was developed using coded competencies from interview data. In order to identify competencies that would fit with the other two components of effective job performance, organizational environment factors such as vision, strategies and policies, and job demand factors 
such as the job description, were used as criteria for rating the competencies in the questionnaire. The respondents were asked to rate each competency based on importance to effective job performance, and that would be supportive of organizational environment and job demands. Since this study aimed to determine a competency model that would fit the requirements of the job in both current and future terms, respondents were asked to rate each competency on level of importance to present effective job performance and in the future (ten years from now). To check the comprehensiveness of the competencies, respondents were also requested to give their opinions and suggestions on the given competencies and key behavioral indicators.

5. Finally, a job competency model was compiled for further application.

\section{DATA ANAL YSIS}

The results of the study were divided into two parts: Behavioral Event Interviews and competency model survey. The first analysis was performed with qualitative data from the Behavioral Event Interviews (BEI). The BEI narratives were analyzed and coded to identify the competencies that superior employees employed on the job. Results from the BEI data analysis were summarized into a preliminary competency model that was organized by competencies and behavioral indicators. This preliminary list of competencies was then validated through a competency model survey using a questionnaire developed from the list of competencies. Respondents who were key stakeholders in the Department were asked to rate the importance of each competency to effective performance on the job. The second analysis was conducted using quantitative data from the competency model survey. Statistical analyses were performed on the scores of the competencies. The purpose of these analyses was to assess if the competencies had achieved an acceptable level of reliability and really represented effective characteristics required by the job. The results from the questionnaire data analysis were then used in preparation of the final competency model for this position level. A summary is shown below. 
Identify Super Stars or

Superior Performers

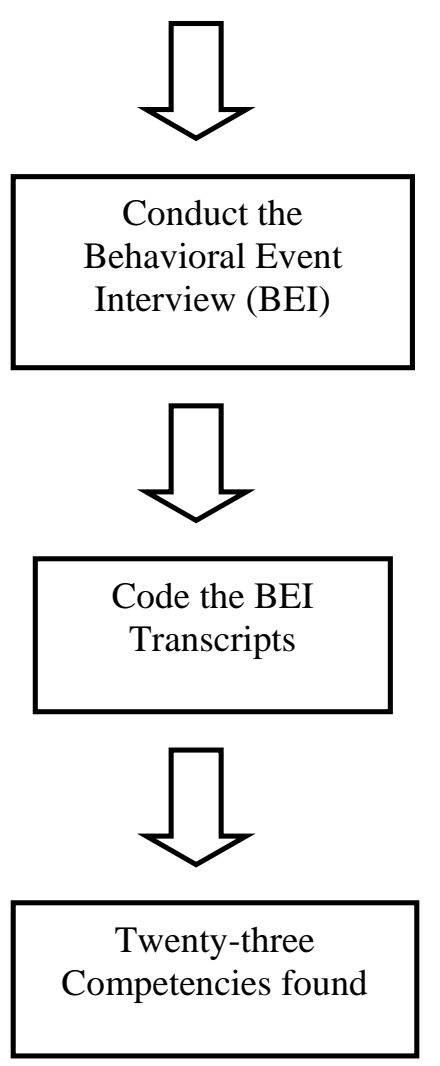

Validate the Preliminary

Competency Model

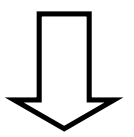

All Twenty-three Competencies Required

Figure 5 Summary of the Research

There are three major parts to the summary of the research findings: Behavioral Event Interviews, Competency Model Survey and Training Needs.

\section{Behavioral Event Interviews: A Preliminary Competency Model}

After using thematic analysis methods to analyze the BEI descriptions, it was found that there were twenty-three competencies exhibited by the superior job performers in this study. Those competencies were "Developing others", "Organizational Awareness", Achievement Orientation”, "Professional Expertise”, "Self-Improvement”, "Team Leadership”, "Directiveness", "Interpersonal Understanding”, Relationship Building and Coordination”, “Organizational Commitment”, “Initiative”, "Flexibility”, “Self- 
Confidence”, “Communication and Influence”, "IT and Computer Literacy”, "ServiceMinded” “Analytical Thinking”, "Integrity”, “Concern for Order, Quality, and Accuracy”, “Information Seeking”, "Self-Control”, “Conceptual Thinking”, and "English Skills" respectively. The most frequently found competency from the BEI descriptions was "Developing others" (80.00\%) whereas rarely seen competencies were "SelfControl”, “Conceptual Thinking” and "English Skills” (10.00\%).

\section{Competency Model Survey: Validating a Preliminary Competency Model}

After the mean score and standard deviation of each competency had been calculated, all twenty-three competencies scored above average. Every competency theme received a mean score of over 3.00 for both present and future perspectives. The competency that received the highest mean score for present was "Service-Minded" (4.57) while "English Skills" derived the lowest mean score (3.11). The competency that received the highest mean score for importance for the future was "Concern for Order, Quality, and Accuracy” (4.89), whereas "English Skills” got the lowest mean score (3.41).

\section{Employee Training Needs}

Employee training needs were assessed by analyzing the BEI data and the answers to the open ended questions. Many training programs were suggested by respondents, these were: "Work/Budget Planning and Management", "Monitoring and Evaluating Systems”, “General Management”, "Professional Knowledge”, "Finance and Accounting”, "Provision and Procurement”, "Concerned Laws or Regulations", "IT Programs and the Internet”, "Integrity”, "Good Governance”, "Public Sector Management in Current Bureaucratic Reform”, “Change Management”, “Achievement Orientation Management”, “The Effective Way to Manage Organizational Resources”, "Human Resource Management”, “Data Analysis and Synthesis”, "English skills”, "Public Relations”, “Communication Skills”, “Teamwork”, “Coordinating and Building Relationship", "Meeting Arrangements”, "Self-Control”, and "How to Create Vision and Work Improvement”. A summary of results is illustrated in the following figure: 


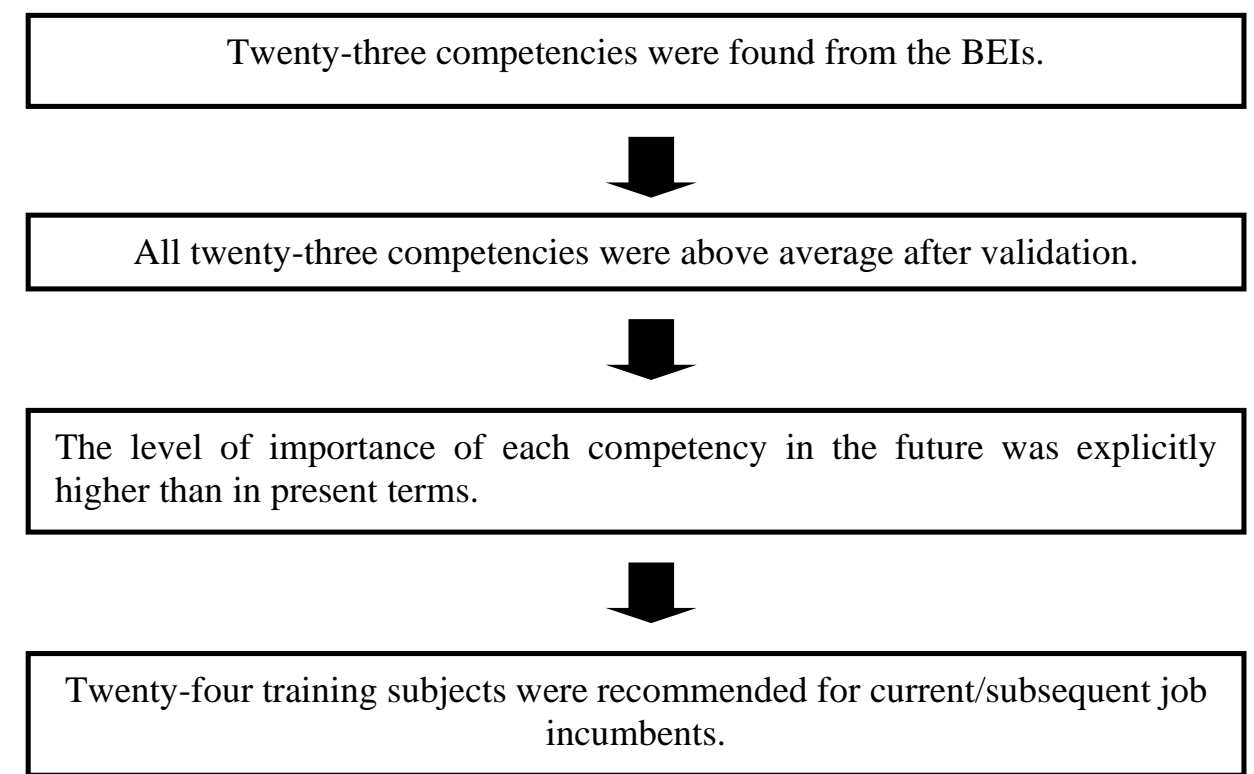

Figure 6 The Results of this Study

When the competency study was complete the resulting final competency model consisted of a set of competencies and key behavioral indicators. The original competency model that Spencer and Spencer (1993) identified was organized into three to six clusters containing twelve to twenty-seven competencies, each with three to seven behavioral indicators. Based on the above findings, the researchers recommend a competency model for the position level of Chief of General Administrative Sub-Division, an entry-level manager position in the Thai Department of Agriculture. In this case, the results of the study revealed that all twenty-three competencies were required for both present and future job performance. However, Spencer and Spencer (1993) propose that long "laundry lists" of competencies are less useful than shorter, better-focused lists of the most essential items and irrelevant competencies or levels should be omitted. An efficient competency model, according to Spencer and Spencer, lists the five to nine most important competencies and, for this reason, the researchers used current level of importance (the level of importance of each competency at present) as primary information to recommend nine competencies in the suggested competency model. The nine competencies that received the highest mean scores (for level of importance at present) are recommended as the required competencies for effective job performance. 


\section{RECOMMENDATIONS AND IMPLICATIONS}

The recommended competency model can be organized into four types of competency characteristics: motives, self-concept, knowledge, and skills and ability as follows:

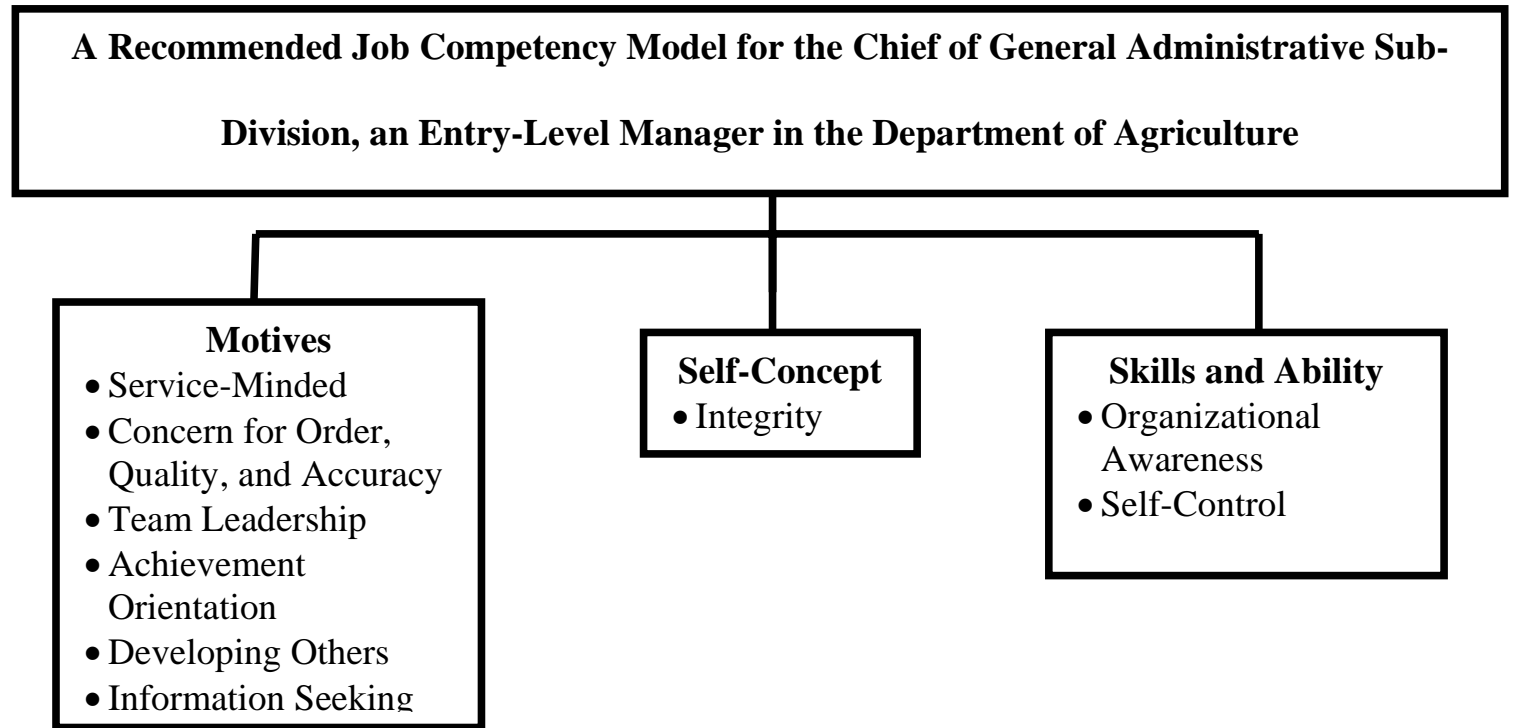

Figure 7 Recommended Job Competency Model for the Chief of General Administrative Sub-Division position level, an Entry-Level Manager position in the Department of

Agriculture

\section{Motives}

1. Service-Minded: A desire to help or serve others, to meet their needs. Focusing efforts on discovering and meeting customer or client needs.

- Responds appropriately to customer inquiries, requests or complaints

- Acts to makes things better for the customer

- Takes actions to satisfy customers and give them confidence in his/her intentions and those of the organization

- Takes personal responsibility to meet customer needs and resolve problems

2. Concern for Order, Quality and Accuracy: An underlying drive to reduce uncertainty in the surrounding environment.

- Keeps an organized workspace; maintains an orderly workspace 
- Monitors/checks quality and accuracy of work or information

- Develops and uses systems to increase order and ensure that procedures are followed

3.Team Leadership: An intention to take a role as leader of a team or other group. A desire to lead others.

- Encourages others to work together as a team

- Acts to promote a teamwork climate

- Keeps associates informed about relevant or useful information, lets them know what is happening for benefit of work

- Promotes team morale and productivity: models desired behavior: demonstrates personal commitment to the team

4. Achievement Orientation: A concern for working well or for competing against a standard set by management.

- Continuously improves working procedures to increase efficiency

- Sets work plans and takes actions to reach challenging goals for self or subordinates

- Takes advantages of available resources to complete work efficiently

5.Developing Others: Intent to teach or to foster the development of one or several other people.

- Acts to support learning and development of subordinates, e.g. provides training, gives task-oriented instructions, directions, coaching and demonstrations, and provides supports to increase working effectiveness

- Gives negative and positive feedback in work performance and behavior for improvement to subordinates

- Allocates task responsibility in appropriate areas to appropriate individuals

6.Information Seeking: An underlying curiosity, a desire to know more about things, people or issues. Makes an effort to get more information.

- Seeks and scans for work-related information

- Finds miscellaneous useful information and potential opportunities that may be of future use

\section{Self-Concept}

1. Integrity: A personal belief in righteousness.

- Keeps commitments 
- Demonstrates honesty and transparency

- Acts in a consistent manner

- Behaves oneself as a good government official

- Acts to gain confidence and trust from superiors and colleagues

\section{Skills and Ability}

2. Organizational Awareness: An ability to understand the power relationships in his or her own organization or in other organizations.

- Understands the organizational formal structure: the chain of command, positional power, rules, regulations and standard operating procedure

- Understands underlying organizational issues or on-going problems, opportunities and political forces affecting the organization

3. Self-Control: An ability to keep emotions under control and to restrain negative actions when tempted, when faced with opposition or hostility from others, or when working under conditions of stress.

- Shows tolerance; remains calm and patient in stressful situations

- Controls own feelings and temper in all situations

- Responds constructively to problems even under stress

\section{CONCLUSIONS}

The competency model and implications derived from the findings of this study should be valuable to the Thai Department of Agriculture or others concerned in developing the competence of job incumbents and maximizing competent performance in an organization. In order to obtain effective performance at this position level, the Department needs to have job incumbents well equipped with these competencies. The researchers recommend that the Department incorporates the competencies identified above into its future competency-based human resource management plan as detailed as follows.

First, it is essential that competencies be included in job descriptions because a list of job responsibilities and the results of job tasks are not sufficient measures to ensure success; rather well-defined skill competencies for a position encourage job incumbents to work more effectively (Tas et al., 1996). This study provides a competency model consisting of a list of competencies needed at this position level, therefore an effective job description for the Chief of General Administrative Sub-Division position level in the 
Thai Department of Agriculture should include the required competencies.

Second, the findings of this study demonstrate the need for a competency-based curriculum addressing the areas of the twenty-three competencies required in this position. Additionally, when the data on training needs was analyzed, it was found that multiple training courses were recommended. Although the current incumbents may have the opportunity to attend a number of training courses, very few have access to formal training designed for this position. In order to succeed in implementing human resource development through a competency-based approach, the Department could design a number of specific curriculums based on the required competencies. When validating the competency model the results of the data analysis showed that "Service-Minded" and "Concern for Order, Quality, and Accuracy" received the highest mean scores respectively in terms of level of importance to effective performance in the job, both at present and in the future. It was noticeable that these results contradicted findings from the BEI analysis, which revealed that both these mentioned competencies were rarely experienced among superior performers. This implication may provide other basic information for the Department in that these kinds of characteristics should be given attention during competency enhancement.

Third, after competency-based models are compiled, developing competencies in individuals is the next important step in building the working capability of the employees in an organization. The next step is to design cost-effective training interventions that can develop the required competencies. Competency-based training and development is an approach that includes formal training programs, development center feedback, selfdevelopment resource guides, computer and interactive video-assisted self-instruction, job assignments, mentoring relationships, and organizational structure, process and culture interventions designed to increase individual competencies (Spencer \& Spencer, 1993).

A formal competency-based training program can be designed and conducted as a one or two-day classroom course led by a trainer, using adult experiential learning inputs: reading, lectures, live or video demonstrations, instrumented feedback, role plays and simulations, and self-assessment reflection exercises (Spencer \& Spencer, 1993). An action-learning based program is another way of motivating employee competency enhancement through the development of experience-based training that offers a more meaningful result than other training and development options. Action-learning can be carried out by letting job holders perform meaningful tasks and sharing the learning experiences. The design of an action-learning format should accommodate the 
competencies needed both in the present and in future. Determining probable future organizational scenarios and the competencies needed to manage them will be the product of the business strategist (Tas et al., 1996).

Finally, apart from training and development, a competency model can be used by an organization in a variety of ways. For example, this model can be used for selection, performance management, compensation, career development, succession planning and management information systems (Spencer \& Spencer, 1993).

\section{REFERENCES}

Bartram, D. (2004). Assessment in Organizations. Applied Psychology: An International Review, 53(2), p. 237-259.

Bartram, D., Robertson, I. T., \& Callinan, M. (2002). Introduction: A Framework for Examining Organizational Effectiveness. In I.T. Robertson, M. Callinan, \& D. Bartram (Eds.), Organizational Effectiveness: The Role of Psychology (p. 1-12). Chichester, UK: Wiley.

Berger, L., \& Berger, D. (2004). The Talent Management Handbook. Creating Organizational Excellence by Identifying, Developing, and Promoting Your Best People. New York: Mcgraw-Hill.

Boyatzis, R. (1982). The Competent Manager: A Model for Effective Performance. New York: John Wiley \& Sons.

Bueno, C. and Tubbs, S. (2004). Identifying Global Leadership Competencies: An Exploratory Study. Journal of American Academy of Business. Sep. 2004, 5(1/2), p. 80-87.

Carretta, A. (1992). Career and Succession Planning. In: Mitrani, A., Dalziel, M., and Fitt, D. Competency Based Human Resource Management. HayGroup. 1992.

Cummings, T., \& Worley, C. (2001). Organization Development and Change. Ohio: South-Western College Publishing.

Gould-Williams, J. (2003). The Importance of HR Practices and Workplace Trust in Achieving Superior Performance: A Study of Public-Sector Organizations. International Journal of Human Resource Management, 14:1 February, p. 28-54.

HayGroup. (2004). Hay Resources Direct. http://www.hayresourcesdirect.haygroup.com/Competency/Assessments_Surveys /Manager_Comp...

Ichniowski, C., Kochan, T.A., Levine, D., Olson, C., \& Strauss, G. (1996). What Works at Work: Overview and Assessment. Industrial Relations, 35(3), p. 299-333. 
Ivancevich, J. (2003). Human Resource Management. New York: Mcgraw-Hill.

McClelland, D.C. (1973). Testing for Competence Rather Than for Intelligence. American Psychologist, 28, p. 1-14.

Mitrani, A., Dalziel, M., \& Fitt, D. (1992). Competency Based Human Resource Management. HayGroup.

Office of Civil Service Commission. (2003). Research Study to Develop Policies, Mechanisms and Follow-up Evaluation of Government Officials Development. Office of Civil Service Commission. Bangkok.

Office of Civil Service Commission. (2003-2004). The Handbook for Developing Civil Servant Development Strategic Plan. Office of Civil Service Commission. Bangkok.

Puwittayaphan, A. (2004). Career Development in Practice. HR Center Company Limited. Bangkok.

Rao, T.V. (2000a). Human Resource Development - Concept and Background, Human

Resources Development: Experiences, Interventions and Strategies, New Delhi: Sage Publications.

Rassametummachot, S. (2005). Competency-Based Learning. Se-Education Public Company Limited. Bangkok.

Rodrigues, L. L. R., \& Chincholkar, A. M. (2005). Benchmarking the HR Practices of an Engineering Institute with Public Sector Industry for Performance Enhancement. International Journal of Training and Development, 9:1, p. 6-20.

Saenthong, N. (2004). Competency. HR Center Company Limited. Bangkok.

Simpson, B. (2002). The Knowledge Needs of Innovating Organizations. The University of Auckland.

Society for Human Resource Management. (2003). Competency Overview. http://www.Competencies\%20Overview.htm

Spencer, L. \& Spencer, S. (1993). Competence at Work: Models for Superior Performance. New York: John Wiley \& Sons, Inc.

Tas, Richard F., LaBrecque, Suzanne V., Clayton, \& Howard R. (1996). PropertyManagement Competencies for Management Trainees. Cornell Hotel and Restaurant Administration Quarterly. US.

Thomson, A., \& Strickland, A. (2004). Strategic Management. New York: Mcgraw-Hill.

United Nations Industrial Development Organization. (2002). UNIDO Competencies. http://www.unido.org.

Woodruffe, C. (1992). What is Meant by Competency? In: Sparrow, P.R., Boam, R., Eds. Designing and Achieving Competency. McGraw-Hill International.UK. 